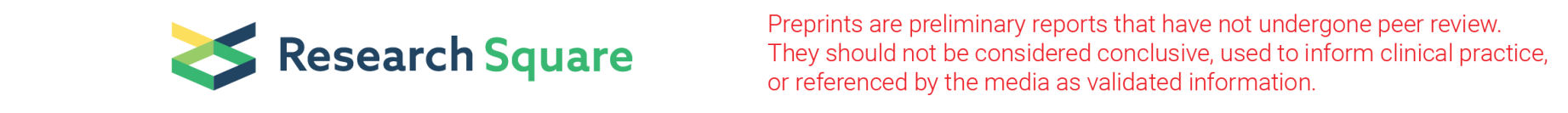

\title{
Evaluation of Prenatal Central Nervous System Anomalies: Obstetric Management, Fetal Outcomes and Chromosome Abnormalities
}

\author{
Ann Gee Tan \\ University of Malaya \\ Neha Sethi \\ University of Malaya \\ Sofiah Sulaiman ( $\nabla$ sofiahsulaiman@gmail.com ) \\ University of Malaya
}

\section{Research Article}

Keywords: Prenatal ultrasound, central nervous system anomalies, chromosomal abnormality, neurodevelopmental outcome

Posted Date: August 9th, 2021

DOI: https://doi.org/10.21203/rs.3.rs-754084/v1

License: (c) (i) This work is licensed under a Creative Commons Attribution 4.0 International License. Read Full License

Version of Record: A version of this preprint was published at BMC Pregnancy and Childbirth on March 15th, 2022. See the published version at https://doi.org/10.1186/s12884-022-04555-9. 


\section{Abstract}

Objective: To study the prognostic outcomes of fetuses with prenatally diagnosed central nervous system (CNS) anomalies and describe the obstetric management for those fetuses.

Methods: In this retrospective study, fetuses who were detected to have central nervous system by prenatal ultrasound from January 2010 to December 2019 were recruited. Data regarding prenatal diagnosis and obstetric outcome were retrieved from maternal and paediatric records. Prognosis of children who survived till delivery was classified based on their neurodevelopmental outcome within 2 years of life.

Results: 365 fetuses were prenatally diagnosed with CNS malformations within the 10-year study period, at a mean gestational age of $24.65 \pm 7.37$ weeks at diagnosis. Ventriculomegaly (23.36\%) was the commonest CNS anomalies diagnosed antenatally. 198 (54.20\%) fetuses has associated extra-CNS anomalies, with cardiovascular system being the most common organ system involved with CNS anomalies. Karyotyping was performed in 111 pregnancies, with chromosomal aberrations detected in 53 (49.07\%) cases and culture failure in 3 cases. Edward syndrome and Patau syndrome were commonly associated with CNS anomalies. Fetuses with congenital CNS anomalies and abnormal chromosomal karyotyping more likely to be diagnosed earlier by prenatal ultrasound and tend to have poorer obstetric and neurocognitive prognosis. Among the 279 cases whom their pregnancy outcomes were available, 105 (37.63\%) pregnancies were electively terminated, 35 (12.54\%) pregnancies ended in spontaneous loss while the remaining 139 (49.82\%) cases resulted in live births. The decision of TOP largely depends on mean diagnostic gestational age, presence of chromosomal aberrations and abnormal amniotic fluid volume in those fetuses. Ruling out 21 (15.11\%) cases which were lost to 2-year follow-up, only 75 (53.96\%) infants were still alive by the age of 2 years. Only $32(23.02 \%)$ children with prenatally diagnosed CNS anomalies had normal neurodevelopmental outcome. The presence of multiple CNS anomalies and involvement of extra-CNS anomalies indicated a poorer neurodevelopmental prognosis.

Conclusion: Less than $50 \%$ of fetuses with prenatally diagnosed CNS anomalies resulted in live births. Even if they survive till delivery, majority passed away within 2 years or had neurodevelopmental disability.

\section{Introduction}

Congenital malformations are the leading factor of perinatal death and childhood morbidity $(1-6)$. Ultrasound screening for congenital anomalies has been a routine for all pregnant ladies to reduce the birth of malformed children (7-13), and it is recommended to perform the anomaly scan at 18-22 weeks GA (14-17).

As usually, ultrasound (USG) screening provide reassurance to the couples, less than $5 \%$ of the scans revealed abnormality (4,5,17-19) CNS anomalies accounts for the highest percentage of prenatally detected deformities among all organ systems $(3,4,11,13,20,21)$, with an incidence of 2-10 per 1000 live births (22-25). With the advancement in imaging technologies offering a better resolution of the fetal cerebral structures and enhancement in the skill of sonographers, the detection rate was expected to rise $(14,16,26,27)$.

Prenatal ultrasound and karyotyping findings often serve as the main guide for the prediction of prognostic outcomes and the establishment of management plans for abnormal pregnancies. However, counseling on the prognosis is often difficult as most of the fetuses with these conditions ended up with abortion and neonatal death and there is a lack of studies on longterm follow-up in children born with prenatally diagnosed CNS anomalies $(7,20)$. Therefore, we intend to address the outcome of those fetuses and outline the systemic approach once CNS anomaly is suspected.

\section{Methodology}

This was a retrospective cohort study that was performed at Department of Obstetrics and Gynaecology, University of Malaya Medical Centre (UMMC) between January 2010 and December 2019. All pregnancies that were detected to have any CNS anomaly on ultrasonography at our institution within this ten-year duration were included. 
UMMC was established as a tertiary referral center for pregnant ladies with suspected congenital anomalies to be referred from all over Malaysia. All the ultrasound examinations for prenatal diagnosis of CNS anomalies were performed by sonographers or obstetricians and confirmed by Maternal-Fetal Medicine specialists. All ultrasound examinations were performed using Voluson S8 (Buckinghamshire, United Kingdom) with 2- $5 \mathrm{MHz}$ transabdominal transducer or 4-7 MHz transvaginal transducer. The obstetric USG assessment not focused solely on the central nervous system but included a complete assessment of all morphological structures of the entire fetus. Any deformity noted from the scan was recorded according to respective organ systems. The fetus was considered to have multiple CNS anomalies if two or more CNS malformations were revealed from prenatal scans although the anomalies were closely related. Fetus with both CNS and extraCNS anomalies are classified to have multiple system deformities. Data collected also included gestational age (GA) at prenatal ultrasound diagnosis, maternal age, gravidity, parity, past obstetric and family history, sonographic findings on amniotic fluid volume, and fetal growth parameters.

When prenatal USG revealed any CNS anomaly, the sonographic findings were discussed among multidisciplinary teams to outline the management plan and establish the prognosis before parental counseling was carried out. Karyotyping was recommended in all cases to determine any associated syndromic condition. Chromosomal analysis was best performed prenatally, if not possible, karyotype confirmation would be part of postnatal investigations.

The maternal and infant records were traced to obtain the pregnancy outcomes. Fetuses with congenital CNS anomalies resulted in either termination of pregnancy (TOP), spontaneous abortion, stillbirth, or live birth. Live births were further grouped according to their survival durations.

In our institution, TOP was an option offered to the couples if the prenatal CNS anomaly detected potentially led to fetal or neonatal mortality and/or morbidity. TOP after 24 weeks was allowed for lethal and severely disabling abnormality, i.e. anencephaly. Post-mortem examination following elective and spontaneous abortions was recommended but rejected by all parents.

Survivors in our study that were under follow-up in our center were evaluated via continuous neurodevelopmental assessments by pediatric neurologists and developmental pediatricians. Vision and hearing tests were done by ophthalmologists and Eye, Nose, Throat (ENT) physicians respectively. We reviewed their postnatal reports up to 2 years old or until they passed away, depending on which is earlier. Then, their neurocognitive functions were classified into normal development, motor delay, mental impairment, or motor and mental delay. For children with any significant motor or intellectual delay that was detected before they defaulted follow-up or passed away before 2 years old, they were classified as having abnormal development. If there was no neurological delay observed and they defaulted follow-up or passed away before 2 years old, they were under the "lost to 2-year follow-up" category as we do not assume no abnormality until 2 years old.

\section{Statistics analysis}

The data were analysed using SPSS, Version 12.0 (Statistical Package for Social Sciences, SPSS Inc., Chicago, IL, USA). The data were presented as percentages where appropriate. Pearson's Chi-square test and t-test were used to test the differences between groups. The level of significance was set at $p<0.05$.

\section{Results}

We reported on 363 pregnancies with 365 fetuses of the abnormal nervous system detected from fetal ultrasound performed at Department of Obstetrics and Gynaecology, UMMC from 2010 to 2019.

The average maternal age was $31.26 \pm 5.13$ years at the time of prenatal diagnosis. The diagnostic gestational age of fetuses ranged from 10 weeks to 39 weeks, with a mean of $24.65 \pm 7.37$ weeks. 
$31.40 \%$ (114/363) women were primigravida; whereas among the remaining 249 women, 90 (36.14\%) of them experienced previous pregnancy loss and $226(90.71 \%)$ women had at least one surviving child. However, only in 8 women, there was a positive family history of CNS or chromosomal anomalies.

The prenatal ultrasonography represented 27 different malformations that occurred 488 times in 365 fetuses and their distributions were described in Table 1. Overall, the commonest CNS anomaly detected on prenatal ultrasound was ventriculomegaly, which comprised 28 mild, 13 moderate, and 38 severe cases while the severity of the rest of 35 cases was unclassified. Based on the prenatal ultrasonographic findings, 198 (54.2\%) had CNS anomalies that were associated with other systems' anomalies, predominantly with cardiovascular system (20.37\%), extremities (16.44\%), and facial (15.51\%) defects (Table 2). In the remaining 167 fetuses with isolated CNS anomalies, 33 (19.7\%) of them were complicated with more than a single type of CNS anomalies. Anencephaly (87.80\%) and cystic hygroma (53.33\%) often occurred in isolation while microcephaly (85.71\%), holoprosencephaly (82.85\%), spinal malformations (82.76\%), and agenesis of corpus callosum $(81.25 \%)$ were predominantly associated with other systems' anomalies (Table 1). Other anomalies were negligible due to insufficient data to make an inference.

Table 1

Distributions of 488 CNS anomalies in 365 fetuses 


\begin{tabular}{|c|c|c|c|c|}
\hline \multirow[t]{2}{*}{ Types of CNS anomalies } & \multicolumn{2}{|l|}{$\begin{array}{l}\text { Isolated CNS } \\
\text { malformation }\end{array}$} & \multirow[t]{2}{*}{$\begin{array}{l}\text { Multiple system } \\
\text { malformations }\end{array}$} & \multirow[t]{2}{*}{$\begin{array}{l}\text { Total } \\
\text { (n) }\end{array}$} \\
\hline & Single CNS anomaly & $\begin{array}{l}\text { Multiple CNS } \\
\text { anomaly }\end{array}$ & & \\
\hline \multicolumn{5}{|l|}{ Neural tube defect } \\
\hline - Anencephaly & 36 & 1 & 4 & 41 \\
\hline - Encephalocele & 9 & 6 & 9 & 24 \\
\hline -Meningocele & 1 & - & - & 1 \\
\hline -Myelomeningocele & 1 & 9 & 8 & 18 \\
\hline -Spina bifida occulta & - & - & 1 & 1 \\
\hline -Closed spina bifida & 1 & - & - & 1 \\
\hline -Unclassified & 1 & 6 & 5 & 12 \\
\hline Ventriculomegaly & 29 & 24 & 61 & 114 \\
\hline Holoprosencephaly & 5 & 1 & 29 & 35 \\
\hline Microcephaly & - & 2 & 12 & 14 \\
\hline \multicolumn{5}{|l|}{ Cysts } \\
\hline - arachnoid cyst & 4 & - & 3 & 7 \\
\hline - choroid plexus cyst & 1 & - & 10 & 11 \\
\hline Cystic hygroma & - & 8 & 10 & 60 \\
\hline $\begin{array}{l}\text { Chiari Type II } \\
\text { malformation }\end{array}$ & - & - & 2 & 18 \\
\hline $\begin{array}{l}\text { Dandy Walker } \\
\text { malformation }\end{array}$ & 4 & 1 & 17 & 22 \\
\hline Cerebellar disorder & - & 5 & 14 & 19 \\
\hline Megacisterna magna & 1 & 4 & 18 & 23 \\
\hline $\begin{array}{l}\text { Agenesis of corpus } \\
\text { callosum }\end{array}$ & - & 3 & 13 & 16 \\
\hline $\begin{array}{l}\text { Other spinal } \\
\text { malformations }\end{array}$ & 4 & 1 & 24 & 29 \\
\hline \multicolumn{5}{|l|}{ Miscellaneous } \\
\hline -sacrococcygeal teratoma & 4 & - & 1 & 5 \\
\hline -cerebral atrophy & - & - & 2 & 2 \\
\hline -wide CSP & - & - & 3 & 3 \\
\hline -absent CSP & - & 3 & 5 & 8 \\
\hline -megalencephaly & - & - & 1 & 1 \\
\hline -hydranencephaly & - & - & 1 & 1 \\
\hline -intracranial haemorrhage & - & 1 & - & 1 \\
\hline -intracranial tumour & 1 & - & - & 1 \\
\hline
\end{tabular}


Table 2

Distributions of 432 extra-central nervous system anomalies in 198 fetuses

\begin{tabular}{|ll|}
\hline Organ systems & Frequency $(\mathrm{n}, \%)$ \\
\hline Cardiovascular & $88(20.37)$ \\
\hline Extremities & $71(16.44)$ \\
\hline Facial & $67(15.51)$ \\
\hline Skull & $55(12.73)$ \\
\hline Gastrointestinal & $36(8.33)$ \\
\hline Musculoskeletal & $33(7.64)$ \\
\hline Respiratory & $33(7.64)$ \\
\hline Renal & $27(6.25)$ \\
\hline Umbilicus & $11(2.55)$ \\
\hline Placenta & $4(0.93)$ \\
\hline Hepatobiliary & $4(0.93)$ \\
\hline Genitourinary & $3(0.69)$ \\
\hline Total & $432(100)$ \\
\hline
\end{tabular}

Of the pregnancies, 67 of them were thought to have abnormal amount of amniotic fluid at the time of ultrasonography; polyhydramnios $(n=41,11.29 \%)$ appeared more frequently than oligohydramnios $(n=26,7.16 \%)$. Intrauterine growth restriction occurred in $28(7.67 \%)$ fetuses while $2(0.55 \%)$ of anomalous fetuses were found to be larger than gestational age on prenatal ultrasonography.

Chromosomal analysis was attempted in 111 (30.41\%) fetuses (Table 3). Of the karyotype analysis, 87 (78.38\%) cases were performed prenatally via amniocentesis $(98.20 \%)$ ) and chorionic villous sampling (1.80\%), whereas $24(21.62 \%)$ cases were analyzed cytogenetically from neonatal tissue or blood samples. Ruling out three culture failures, abnormal karyotypes were recognized in 53 (49.07\%) of 108 cases karyotyped. Edward syndrome $(n=23,43.40 \%)$ and Patau syndrome $(n=14,26.42 \%)$ were the commonest chromosomal aberrations in fetuses with CNS anomalies. Specific CNS anomaly shed light on the possibility of certain chromosomal abnormalities. Our study revealed a close relationship between holoprosencephaly with Patau syndrome, choroid plexus cyst with Edward syndrome, cystic hygroma with Turner syndrome, and megacisterna magna with Edward syndrome.

Table 3

Chromosomal abnormalities in 87 cases 


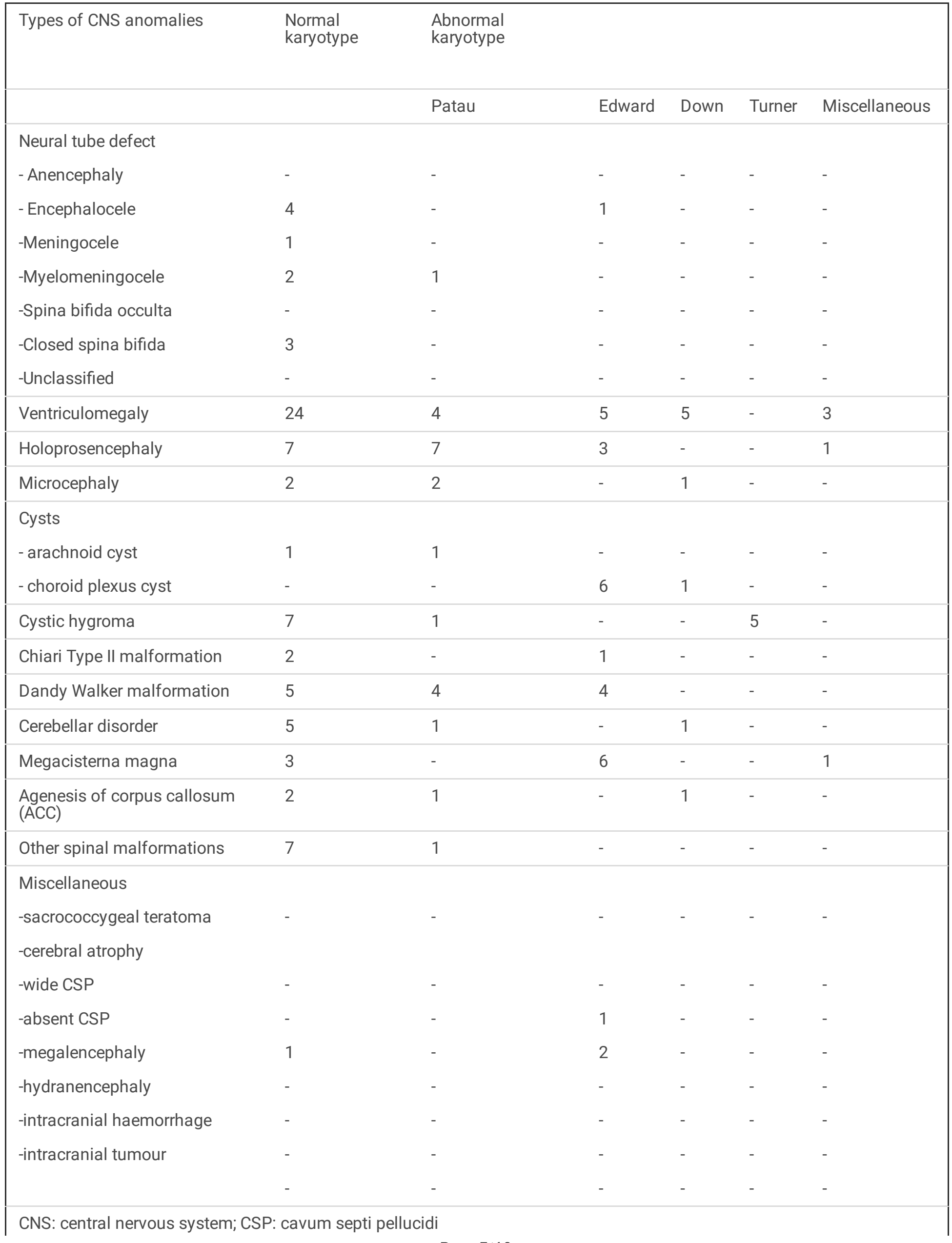


We identified 279 fetuses for whom the obstetric outcomes could be found from retrospective tracing (Table 4). The survival of anomalous fetuses was only achieved in 139 (49.82\%) due to the high rate of induced TOP $(n=105,37.63 \%)$ with additional 35 (12.54\%) spontaneous fetal demise (8 intrauterine fetal death; 27 stillbirths). Moreover, 36 of the neonates died in the first month after birth, 3 of them survived till less than 6 months in life and 4 infants were alive for more than 6 months but less than a year. Only 75 live births remained alive after 2 years since birth. 21 live births were lost to follow-up, thus their survival durations remained undetermined.

Table 4

Obstetric outcomes in 279 fetuses 


\begin{tabular}{|c|c|c|c|c|c|c|c|c|c|c|}
\hline Types of CNS & TOP & & IUFD & SB & LB & & & & & \\
\hline & $\begin{array}{l}(<24 \\
\text { wks })\end{array}$ & $\begin{array}{l}(>24 \\
\text { wks })\end{array}$ & & & $\begin{array}{l}<1 \text { mth } \\
\text { survival }\end{array}$ & $\begin{array}{l}1 \text { mth to } \\
<6 \text { mths } \\
\text { survival }\end{array}$ & $\begin{array}{l}6 \text { mths< } \\
1 \mathrm{yr} \\
\text { survival }\end{array}$ & $\begin{array}{l}1-2 \text { yrs } \\
\text { survival }\end{array}$ & $\begin{array}{l}>2 \\
\text { yrssurvival }\end{array}$ & $\begin{array}{l}\text { Lost } \\
\text { to } \\
\text { follow- } \\
\text { up }\end{array}$ \\
\hline \multicolumn{11}{|l|}{ Neural tube defect } \\
\hline - Anencephaly & 22 & 9 & - & 2 & - & 3 & - & - & - & - \\
\hline - Encephalocele & 10 & 3 & - & 2 & - & - & - & - & 3 & 1 \\
\hline -Meningocele & - & - & - & - & - & - & - & - & 1 & - \\
\hline - Myelomeningocele & 3 & - & - & 1 & 3 & - & - & - & 6 & 3 \\
\hline $\begin{array}{l}\text {-Spina bifida } \\
\text { occulta }\end{array}$ & - & - & - & - & - & - & - & - & $\begin{array}{l}1 \\
1\end{array}$ & - \\
\hline $\begin{array}{l}\text {-Closed spina } \\
\text { bifida }\end{array}$ & 2 & 2 & - & 1 & 1 & - & - & - & 6 & - \\
\hline \multicolumn{11}{|l|}{-Unclassified } \\
\hline Ventriculomegaly & 4 & 8 & - & 7 & 14 & 3 & 4 & - & 45 & 11 \\
\hline Holoprosencephaly & 6 & 4 & 1 & 2 & 8 & - & - & - & 3 & 1 \\
\hline Microcephaly & 2 & 1 & - & 1 & 4 & - & - & - & - & 1 \\
\hline \multicolumn{11}{|l|}{ Cysts } \\
\hline - arachnoid cyst & - & - & - & 2 & 1 & - & - & - & 2 & - \\
\hline $\begin{array}{l}\text { - choroid plexus } \\
\text { cyst }\end{array}$ & 2 & 1 & - & 1 & 1 & - & - & - & 2 & - \\
\hline Cystic hygroma & 18 & 1 & 6 & 3 & 1 & - & - & - & 8 & 3 \\
\hline $\begin{array}{l}\text { Chiari Type II } \\
\text { malformation }\end{array}$ & 3 & 3 & - & 2 & 1 & - & - & - & 7 & 1 \\
\hline $\begin{array}{l}\text { Dandy Walker } \\
\text { malformation }\end{array}$ & - & 3 & - & 5 & 4 & - & - & - & 4 & 1 \\
\hline Cerebellar disorder & - & 2 & 1 & 2 & 3 & 2 & 1 & - & 3 & - \\
\hline $\begin{array}{l}\text { Megacisterna } \\
\text { magna }\end{array}$ & - & 2 & - & 2 & 2 & 1 & - & - & 4 & 1 \\
\hline $\begin{array}{l}\text { Agenesis of corpus } \\
\text { callosum }\end{array}$ & 3 & 4 & - & - & 2 & - & 1 & - & 3 & 1 \\
\hline $\begin{array}{l}\text { Other spinal } \\
\text { malformations }\end{array}$ & 8 & 4 & - & 3 & 5 & - & - & - & 1 & 2 \\
\hline \multicolumn{11}{|l|}{ Miscellaneous } \\
\hline $\begin{array}{l}\text {-sacrococcygeal } \\
\text { teratoma }\end{array}$ & 1 & - & - & - & - & - & - & - & 2 & 1 \\
\hline $\begin{array}{l}\text {-cerebral atrophy } \\
\text {-wide CSP }\end{array}$ & - & - & - & - & - & 1 & - & - & 1 & - \\
\hline -absent CSP & - & - & - & 1 & - & - & - & - & 1 & - \\
\hline -megalencephaly & 1 & - & - & - & 1 & - & - & - & 3 & - \\
\hline
\end{tabular}




\begin{tabular}{|c|c|c|c|c|c|c|c|c|c|c|}
\hline -hydranencephaly & - & - & - & - & - & - & - & - & 1 & - \\
\hline -intracranial & - & - & - & - & 1 & - & - & - & - & - \\
\hline $\begin{array}{l}\text {-intracranial } \\
\text { tumour }\end{array}$ & - & - & - & - & 1 & - & - & - & - & - \\
\hline & - & - & - & - & - & - & - & - & - & - \\
\hline
\end{tabular}

CNS: central nervous system; CSP: cavum septi pellucidi; wks, weeks; mths, months

Follow-up data on delivery methods were available for 257 fetuses involved in the study. The fetuses were delivered at the average GA of $30.90 \pm 8.49$ weeks. In specific, the mean GA for elective TOP, intra-uterine fetal loss, and live births were $21.93 \pm 5.99$ weeks, $30.71 \pm 7.32$ weeks, and $37.15 \pm 2.71$ weeks respectively. In 124 cases of elective and spontaneous termination of pregnancy, $115(92.74 \%)$ cases were performed vaginally via medical induction and $9(7.26 \%)$ cases required surgical evacuation on the conception. On the other hand, live births were delivered more frequently through Caesarean section $(n=78,58.65 \%)$ than vaginal delivery $(n=55,41.35 \%)$.

139 surviving infants were classified according to their respective functional status based on two-year neurodevelopmental assessments (Table 5). Normal neurologic development was achieved in $32(23.02 \%)$ children. Functionally abnormal children included 14 (10.07\%) cases with pure motor disability, 9 (6.47\%) cases with pure mental disability as well as $31(22.30 \%)$ children with both motor and intellectual impairments. The remaining $53(38.13 \%)$ children did not have any significant abnormality detected before they defaulted neurodevelopmental follow-up or passed away before 2 years old, therefore classified as "lost to follow-up" in Table 5. Among those children with neurological deficit, complete paralyzation, bladder and/or bowel incontinence, psychiatric disorder, epilepsy, hearing loss, and vision problems were reported in 17, 11, 7, 7, 6, and 12 children respectively.

Table 5

Two-year neurodevelopmental outcomes of 139 surviving infants 


\begin{tabular}{|c|c|c|c|c|c|}
\hline $\begin{array}{l}\text { Types of CNS } \\
\text { anomalies }\end{array}$ & $\begin{array}{l}\text { Normal } \\
\text { Development }\end{array}$ & $\begin{array}{l}\text { Motor } \\
\text { disability }\end{array}$ & $\begin{array}{l}\text { Mental } \\
\text { disability }\end{array}$ & $\begin{array}{l}\text { Psychomotor } \\
\text { disability }\end{array}$ & $\begin{array}{l}\text { Lost to follow- } \\
\text { up }\end{array}$ \\
\hline \multicolumn{6}{|l|}{ Neural tube defect } \\
\hline - Anencephaly & - & - & - & - & 3 \\
\hline - Encephalocele & - & 1 & 1 & 2 & - \\
\hline -Meningocele & - & - & - & 1 & - \\
\hline -Myelomeningocele & 1 & 3 & - & 3 & 5 \\
\hline -Spina bifida occulta & 1 & - & - & - & - \\
\hline -Closed spina bifida & - & 1 & - & - & - \\
\hline -Unclassified & 2 & 3 & - & 1 & 1 \\
\hline Ventriculomegaly & 16 & 9 & 7 & 19 & 26 \\
\hline Holoprosencephaly & - & 2 & - & 2 & 8 \\
\hline Microcephaly & - & - & - & 1 & 4 \\
\hline \multicolumn{6}{|l|}{ Cysts } \\
\hline - arachnoid cyst & 2 & - & - & - & 1 \\
\hline - choroid plexus cyst & 1 & - & - & 1 & 1 \\
\hline Cystic hygroma & 8 & - & - & 2 & 2 \\
\hline $\begin{array}{l}\text { Chiari Type II } \\
\text { malformation }\end{array}$ & 1 & 3 & - & 3 & 2 \\
\hline $\begin{array}{l}\text { Dandy Walker } \\
\text { malformation }\end{array}$ & 2 & - & 1 & 1 & 5 \\
\hline Cerebellar disorder & - & - & - & 3 & 6 \\
\hline Megacisterna magna & 1 & 1 & - & 3 & 3 \\
\hline $\begin{array}{l}\text { Agenesis of corpus } \\
\text { callosum }\end{array}$ & - & 2 & - & 3 & 2 \\
\hline $\begin{array}{l}\text { Other spinal } \\
\text { malformations }\end{array}$ & 1 & - & - & 1 & 6 \\
\hline \multicolumn{6}{|l|}{ Miscellaneous } \\
\hline $\begin{array}{l}\text {-sacrococcygeal } \\
\text { teratoma }\end{array}$ & 1 & 1 & - & - & 1 \\
\hline -cerebral atrophy & & & & 1 & 1 \\
\hline -wide CSP & & - & 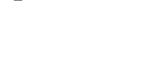 & 1 & 1 \\
\hline -absent CSP & - & - & - & 1 & - \\
\hline -megalencephaly & - & - & - & 3 & 1 \\
\hline -hydranencephaly & - & - & - & 1 & - \\
\hline (10) & - & - & - & - & 1 \\
\hline $\begin{array}{l}\text {-intracranial } \\
\text { haemorrhage }\end{array}$ & - & - & - & - & 1 \\
\hline -intracranial tumour & - & - & - & - & - \\
\hline
\end{tabular}




\section{Discussion}

Hadzagic et al. (8) defined congenital malformation as "any morphological abnormality that dates to the embryonic or fetal period, regardless of the mechanism of its origin ". As radiological technology advances, fetal ultrasonography is an appropriate diagnostic standard for prenatal CNS anomalies and they can be visualized starting from the first trimester, even as early as 6 weeks onwards $(7,17,27-29)$. The detection of CNS anomaly on ultrasound requires a systemic approach to direct into the final diagnosis, evaluate the prognosis of the condition and outline the management plan accordingly.

\section{Fetal magnetic resonance imaging (fMRI)}

There is a concern that under/overdiagnosis might affect the decision on management options and lead to inappropriate TOP (26), thus the prenatal diagnosis established must be precise. Whenever the prenatal prediction by USG is uncertain, $\mathrm{fMRI}$ should be used interchangeably to secure the diagnosis $(7,8,30)$.

\section{Multidisciplinary involvement in genetic counseling}

This is not just the responsibility of obstetricians that will take care of those ladies with affected pregnancies. The management is complex, and the women are best cared for by a multidisciplinary team with good communication between expertise $(7,11,14,30,31)$. Assessment on the neurodevelopmental deficit that the child may suffer if he survives should be determined by neurologists, neonatologists, and pediatricians (30). Geneticists should be involved to evaluate the possibility of the condition being hereditary in nature and assess the risk of recurrence in future pregnancies $(14,30-32)$. Once the management outline is established, genetic counseling with prospective parents is mandatory to provide them the consultant information on the specific disorder (32-35). Joint discussion among clinicians and families has been proven to aid the parents in decision-making $(30,32,36)$. However, the process should be non-directive and the counselors should maintain a neutral position to respect for couples' autonomy. Faced with the diagnosis of CNS disorder, the couples are usually unprepared and breaking this bad news inevitably evokes psychological stress as they are forced to confront the reality, especially when they have to end the pregnancy which can be precious to them $(33,37)$. In lieu of this, collaboration with bereavement counselors and social workers will favor the process.

Parents have few decisions to make after the counseling. They need to decide whether to proceed to further invasive testing, as well as decisions about whether to give their fetuses a chance to live but possibly suffer from morbidity or terminate the pregnancy to avoid the risk of suffering $(30,33)$. Parents should be informed of the risk of their decision made and the possibility of false-positive prenatal diagnosis before they decide to proceed with any therapeutic intervention $(9,30)$.

\section{Factors affecting TOP}

Parents are often faced with the difficulty weighing the severity and survival of the condition (34), and their decision on TOP is affected by various factors $(7,33,38,39)$. When the CNS anomalies were diagnosed before 24 weeks, $62.38 \%$ of them decided to terminate the pregnancy; whereas $84.68 \%$ of the pregnancies diagnosed after 24 weeks were put under conservative management. The GA at prenatal diagnosis significantly affected TOP $(p<0.001)$. There is an increasing incidence of TOP when chromosomal and amniotic fluid abnormalities are present, with significant p-values of $<0.001$ and 0.017 respectively. Maternal age, presence of children, previous uncompleted pregnancies, involvement of additional CNS and extra-CNS anomalies do not significantly influence the consideration of TOP ( $p=0.526,0.981,0.579,0.124,0.936$ respectively).

\section{Very late termination of pregnancy (VLTOP)}


The parental decision-making process takes time $(7,40)$, and our patients took an average of $1.83 \pm 2.20$ weeks to decide on TOP after the prenatal diagnoses were made. In addition, majority $(n=203,55.61 \%)$ of the diagnoses were made only after 24 weeks gestation. Therefore, VLTOP seems to be unavoidable $(7,41)(40)$. It has been shown that CNS anomalies have the highest percentage leading to VLTOP among all systems (40). VLTOP is a subject of ethical debate as TOP after 24 weeks gestation is not accepted in many countries $(8,33,40)$. In contrast, Malaysia has made TOP after 24 weeks legally permissible. Abortion Act 1967 has stated that TOP at any GA is allowed when "there is a substantial risk that if the child were born, he would suffer from such mental or physical abnormalities as to be seriously handicapped". - make sure we copied bulat bulat from

\section{Conservative management}

When the couples decide on conservative management, the clinicians have the responsibility to inform them about the predicted prognosis and possible neurodevelopmental outcome to reduce anxiety when the affected child is delivered. Serial sonographic assessments are crucial to scrutinize any progression of the anomaly that might revise the prognosis as pregnancy advances (42).

\section{In-utero surgery}

Although none of the women in our study opted for in-utero surgery as part of obstetric management, there are various publications that showed that many CNS malformations are surgically treatable by fetal therapeutic surgery $(11,43,44)$. Rapidly advancing Fetal Medicine will soon make fetal surgery a capable modality for the correction of fetal malformations.

\section{Spontaneous abortion}

Even some parents decide to continue the pregnancy or could not make up their minds for TOP, the high frequency of CNS anomalies are incompatible with life and will end up with spontaneous fetal demise $(19,20,45)$. We found an association between the involvement of multiple systems and higher rates of spontaneous abortion with a significant $p$-value of 0.001 .

\section{Infectious etiology}

Although the underlying cause of nervous system malformations remains obscure in the majority of cases $(2,5,7,8,46)$, effort should be put in to establish the aetiology that can revise the recurrence risk. Infectious screening is mandatory to exclude TORCH (toxoplasma, rubella, cytomegalovirus, herpes simplex, and syphilis) exposure during the antenatal period $(7,30,47)$.

\section{Chromosomal anomaly}

Fetal karyotyping should be part of obstetric practices to exclude any chromosomal anomaly (30,47-49), and if it fails, postnatal cytogenic analysis should be carried out (7). An abnormal karyotype is more often present in older women (30.44 years versus 32.26 years, $p=0.074)$ and when multiple anatomic systems are involved $(p<0.001)$. Fetuses with chromosomal anomalies are more likely to be diagnosed earlier (24.6818 weeks versus 26.25 weeks, $p=0.231$ ) and commonly illustrate growth retardation on fetal ultrasonography $(p=0.002)$. In continuing pregnancies with chromosomal anomalies, the obstetric outcome was anticipated to be poorer in the majority of cases, with higher rates of induced $(p<0.001)$ and spontaneous $(p=$ 0.825) loss of pregnancy. Even the pregnancy withstands till delivery, the child is expected to have a higher probability of being neurocognitively abnormal, although the association is not significant due to the small sample size $(p=0.901)$.

\section{Mode of delivery}


It should be bear in mind that maternal well-being is always the priority for clinicians. The pregnancy should not be continued if severe maternal complications happened. Vaginal delivery is encouraged especially when the obstetric outcome is less pleasant as Caesarean section might complicate subsequent pregnancies. In the present study, fetuses that resulted in termination are more often being delivered vaginally. On the contrary, live births were more commonly being delivered via Caesarean section $(p<0.001)$ as complications like cephalopelvic disproportion and rupture of cystic lesion were foreseen in pregnancies complicated with CNS anomalies $(42,50)$.

\section{Post-mortem investigations}

In any pregnancy that results in fetal loss, be it induced or spontaneous abortion, complete post-mortem investigation should not be neglected $(7,10,11,26,30)$. In these cases, autopsy should be recommended to be part of the post-mortem examination to verify and revise the prenatal diagnosis which can provide beneficial information for subsequent pregnancies $(11,14,26)$. However, in our study, all parents were reluctant to proceed with the pathological examination, which is in contrast to the high autopsy rates in other countries (51-54). Given this limitation, magnetic resonance imaging (MRI) has been suggested as a useful adjunct and is increasing in popularity. Recent reviews have shown that post-mortem MRI is as effective as autopsy and is advocated to replace autopsy in reaching the postnatal confirmatory diagnosis when autopsy is denied (14, 55-57). When post-mortem autopsy or MRI is not feasible, thorough gross examination by neonatologists should be performed and photographs of the fetus should be captured for diagnostic purposes (58).

\section{Live births}

When the fetus successfully survives till delivery, cranial ultrasound and MRI of brain and spine should be ordered to confirm the prenatal prediction of the CNS anomaly. The child should have long-term neurodevelopment follow-up under pediatric neurologists and developmental pediatricians. Hearing and visual assessments should be done before the child is discharged home. Speech therapists, physiotherapists, and occupational therapists should be involved if the child suffers from any neurological deficit (30). Most of the children will need to go through at least one surgery to correct CNS defects after birth (30, $59,60)$.

\section{Neurodevelopmental outcomes}

The prognostic outcome of children is often dependent on the severity of anomalies (7), therefore distinguishing the severity of involvement by fetal ultrasonography is of paramount importance. For example, in cases of ventriculomegaly, 80\% $(n=20 / 25)$ of neurodevelopmentally abnormal children were detected prenatally to have moderate and severe ventriculomegaly while $57.14 \%(n=8 / 14)$ of fetuses being diagnosed with mild ventriculomegaly had normal pediatric examinations, $p=0.018$. The overall prognosis also strongly depends on the presence of multiple CNS anomalies and malformations from other organ systems. Fetuses with isolated anomaly and single system anomaly indicate favorable postnatal outcomes as compared to those with multiple CNS anomalies and involvement of multiple organ systems $(p=0.006, p=0.006$ respectively).

\section{Strength}

Prognosticating the long-term neurodevelopmental outcome in children who have prenatally diagnosed CNS anomalies remains a challenge as prenatal diagnostic tools could not determine the functional status and there is limited research on this aspect $(30,33)$. Our study that comprehensively scrutinizes the impact of prenatal CNS anomalies on postnatal life up to 2 years added to literature the useful prognostic information that is often sought by the clinicians and parents during genetic counseling. To the best of our knowledge, this is the largest cohort on prenatal CNS anomalies for live births and dead fetuses with wide spectrums of anomalies. 


\section{Limitations}

We acknowledge a large number of patients in our study that were lost to follow-up, and the neurodevelopmental assessment of the survivors was heterogeneous and performed by different pediatricians with different standards of protocols.

\section{Conclusion}

In the present study, the survival rate in our study is only $49.82 \%$ due to the high rate of TOP and spontaneous abortion, and major portions of the surviving children were moderately or severely disabled. With advanced development in Fetal Medicine, more abnormal fetuses will survive but they are at risk of morbidity and morbidity throughout their life which greatly impact their families, healthcare systems as well as societies $(1,2,4,19,21)$. Primary prevention plays a big role especially in the reduction of the incidence of neural tube defect $(3,7,8,20,61)$, and secondary prevention by routine USG examination to all pregnant ladies should remain the mainstay of obstetrical screening $(1,3,8,40)$.

\section{Abbreviations}

CNS: central nervous system; USG, ultrasound; UMMC, University of Malaya Medical Centre; GA, gestational age; TOP, termination of pregnancy; ENT, Eye, Nose, Throat; VLTOP, very late termination of pregnancy; TORCH, toxoplasma, rubella, cytomegalovirus, herpes simplex, and syphilis; MRI, magnetic resonance imaging; fMRI, fetal magnetic resonance imaging; CSP: cavum septi pellucidi

\section{Declarations}

\section{Ethics approval and consent to participate}

Ethics approval was obtained from the Medical Research Ethics Committee, University Malaya Medical Center (MRECID.NO: 2020121-9561). All patients recruited agreed and signed written consent to participate in this study. All methods were carried out in accordance with relevant guidelines and regulations.

\section{Consent for publication}

Written consent was obtained from the participants for publication of this article.

\section{Availability of data and materials}

The datasets used and/or analysed during the current study are available from the corresponding author on reasonable request.

\section{Competing interests}

The authors declare that they have no competing interests.

\section{Funding}

No funding was obtained for this study.

\section{Authors' contributions}


A.G.T. was the main contributor in writing the manuscript, extracting, analyzing, and interpreting the data. N.S. and S.S. reviewed the manuscript. All authors read and approved the final manuscript.

\section{Acknowledgements}

We would like to acknowledge all the colleagues from Department of Obstetrics and Gynaecology, Department of Radiology, Department of Paediatric, and Department of Pathology at the University of Malaya Medical Centre (UMMC) who contributed to the prenatal and postnatal care of the patients included in this study.

\section{References}

1. Sierra M, Rumbo J, Salazar A, Sarmiento K, Suarez F, Zarante I. Perinatal mortality associated with congenital defects of the central nervous system in Colombia, 2005-2014. J Community Genet. 2019 Oct 29;10(4):515-21.

2. Ajao AE, Adeoye IA. Prevalence, risk factors and outcome of congenital anomalies among neonatal admissions in OGBOMOSO, Nigeria. BMC Pediatr. 2019 Dec 3;19(1):88.

3. Onyambu CK, Tharamba NM. Screening for congenital fetal anomalies in low risk pregnancy: the Kenyatta National Hospital experience. BMC Pregnancy Childbirth. 2018 Dec 23;18(1):180.

4. Khanal GP, Sharma P, Kayastha P, Poudel A. Prevalence and Spectrum of Fetal Congenital Anomalies: A Hospital Based Study from Mid-Western Part of Nepal. Nepal J Radiol. 2019 Dec 31;9(2):2-9.

5. Rankin J. Prevalence of congenital anomalies in five British regions, 1991-99. Arch Dis Child - Fetal Neonatal Ed. 2005 Sep 1;90(5):F374-9.

6. Patra C, Nayek K, Dasgupta M, Karmakar P, Sarkar S. Prevalence of congenital anomalies in neonates and associated risk factors in a tertiary care hospital in eastern India. J Clin Neonatol. 2013;2(3):131.

7. De Catte L, De Keersmaeker B, Claus F. Prenatal Neurologic Anomalies. Pediatr Drugs. 2012 Jun;14(3):143-55.

8. Hadžagić-Ćatibušić F, Maksić H, Užičanin S, Heljić S, Zubčević S, Merhemić Z, et al. Congenital Malformations of the Central Nervous System: Clinical Approach. Bosn J Basic Med Sci. 2008 Nov 20;8(4):356-60.

9. Romosan G, Henriksson E, Rylander A, Valentin L. Diagnostic performance of routine ultrasound screening for fetal abnormalities in an unselected Swedish population in 2000-2005. Ultrasound Obstet Gynecol. 2009 Nov;34(5):526-33.

10. Clayton-Smith J, Farndon PA, McKeown C, Donnai D. Examination of fetuses after induced abortion for fetal abnormality. BMJ. 1990 Feb 3;300(6720):295-7.

11. Tennstedt C, Chaoui R, Bollmann R, Körner H, Dietel M. Correlation of prenatal ultrasound diagnosis and morphological findings of fetal autopsy. Pathol Res Pract. 1998;194(10):721-4.

12. Rydberg C, Tunón K. Detection of fetal abnormalities by second-trimester ultrasound screening in a non-selected population. Acta Obstet Gynecol Scand. 2017 Feb;96(2):176-82.

13. Erős FR, Beke A. Congenital Fetal Anomalies and the Role of Prenatal Ultrasound. In: Congenital Anomalies - From the Embryo to the Neonate. InTech; 2018.

14. Vogt C, Blaas H-GK, Salvesen KÅ, Eik-Nes SH. Comparison between prenatal ultrasound and postmortem findings in fetuses and infants with developmental anomalies. Ultrasound Obstet Gynecol. 2012 Jun;39(6):666-72.

15. Salomon LJ, Alfirevic Z, Berghella V, Bilardo C, Hernandez-Andrade E, Johnsen SL, et al. Practice guidelines for performance of the routine mid-trimester fetal ultrasound scan. Ultrasound Obstet Gynecol. 2011 Jan;37(1):116-26.

16. Kashyap N, Pradhan M, Singh N, Yadav S. Early Detection of Fetal Malformation, a Long Distance Yet to Cover! Present Status and Potential of First Trimester Ultrasonography in Detection of Fetal Congenital Malformation in a Developing Country: Experience at a Tertiary Care Centre in India. J Pregnancy. 2015;2015:1-9.

17. Dulgheroff FF, Peixoto AB, Petrini CG, Caldas TMR da C, Ramos DR, Magalhães FO, et al. Fetal structural anomalies diagnosed during the first, second and third trimesters of pregnancy using ultrasonography: a retrospective cohort study. 
Sao Paulo Med J. 2019 Oct;137(5):391-400.

18. Becker R, Wegner R-D. Detailed screening for fetal anomalies and cardiac defects at the 11-13-week scan. Ultrasound Obstet Gynecol. 2006 Jun;27(6):613-8.

19. Dolk H, Loane M, Garne E. The Prevalence of Congenital Anomalies in Europe. In 2010. p. 349-64.

20. Pinar H, Tatevosyants N, Singer DB. Central Nervous System Malformations in a Perinatal/Neonatal Autopsy Series. Pediatr Dev Pathol. 1998 Jan 10;1(1):42-8.

21. Ameen SK, Alalaf SK, Shabila NP. Pattern of congenital anomalies at birth and their correlations with maternal characteristics in the maternity teaching hospital, Erbil city, Iraq. BMC Pregnancy Childbirth. 2018 Dec 18;18(1):501.

22. Tutus S, Ozyurt S, Yilmaz E, Acmaz G, Akin MA. Evaluation and prevalence of major central nervous system malformations: a retrospective study. North Clin Istanbul. 2014;1(2):78-83.

23. Eke CB, Uche EO, Chinawa JM, Obi IE, Obu HA, Ibekwe RC. Epidemiology of congenital anomalies of the central nervous system in children in Enugu, Nigeria: A retrospective study. Ann Afr Med. 15(3):126-32.

24. Golden GS. Congenital Malformations of the Central Nervous System. In: Textbook of Pediatric Neurology. Boston, MA: Springer US; 1987. p. 87-105.

25. Alicelebić S, Arslanagić A, Mornjaković Z. Central nervous system birth defects in surgically treated infants in Sarajevo region of Bosnia and Herzegovina. Bosn J basic Med Sci. 2007 Nov;7(4):294-300.

26. Hauerberg L, Skibsted L, Grãm N, Maroun LL. Correlation between prenatal diagnosis by ultrasound and fetal autopsy findings in second-trimester abortions. Acta Obstet Gynecol Scand. 2012;91(3):386-90.

27. Ding W-P, Li N, Chen M. Ultrasound Screening of Fetal Anomalies at 11-13 + 6 Weeks. Matern Med. 2020 Jul;2(3):175-80.

28. Blaas H-GK, Eik-Nes SH. Sonoembryology and early prenatal diagnosis of neural anomalies. Prenat Diagn. 2009 Apr;29(4):312-25.

29. Rossi AC, Prefumo F. Correlation between fetal autopsy and prenatal diagnosis by ultrasound: A systematic review. Eur $\mathrm{J}$ Obstet Gynecol Reprod Biol. 2017 Mar;210:201-6.

30. Mighell AS, Johnstone ED, Levene M. Post-natal investigations: management and prognosis for fetuses with CNS anomalies identified in utero excluding neurosurgical problems. Prenat Diagn. 2009 Apr;29(4):442-9.

31. Van den Veyver IB. Prenatally diagnosed developmental abnormalities of the central nervous system and genetic syndromes: A practical review. Prenat Diagn. 2019 Aug 28;39(9):666-78.

32. Dobrescu MA, Burada F, Cucu MG, Riza AL, Chelu G, Plesea RM, et al. Prenatal Genetic Counseling in Congenital Anomalies. In: Congenital Anomalies - From the Embryo to the Neonate. InTech; 2018.

33. Bijma HH, Wildschut HIJ, van der Heide A, Passchier J, Wladimiroff JW, van der Maas PJ. Parental Decision-Making after Ultrasound Diagnosis of a Serious Foetal Abnormality. Fetal Diagn Ther. 2005;20(5):321-7.

34. Carnevale A, Lisker R, Villa AR, Casanueva E, Alonso E. Counselling following diagnosis of a fetal abnormality: Comparison of different clinical specialists in Mexico. Am J Med Genet. 1997;69(1):23-8.

35. Marokakis S, Kasparian NA, Kennedy SE. Prenatal counselling for congenital anomalies: a systematic review. Prenat Diagn. 2016 Jul;36(7):662-71.

36. Salema D, Townsend A, Austin J. Patient decision-making and the role of the prenatal genetic counselor: An exploratory study. J Genet Couns. 2019 Feb;28(1):155-63.

37. Skari H, Malt UF, Bjornland K, Egeland T, Haugen G, Skreden M, et al. Prenatal diagnosis of congenital malformations and parental psychological distress-a prospective longitudinal cohort study. Prenat Diagn. 2006 Nov;26(11):1001-9.

38. Schechtman KB, Gray DL, Baty JD, Rothman SM. Decision-making for termination of pregnancies with fetal anomalies: Analysis of 53,000 pregnancies. Obstet Gynecol. 2002;99(2):216-22.

39. Sheiner E, Shoham-Vardi I, Weitzman D, Gohar J, Carmi R. Decisions regarding pregnancy termination among Bedouin couples referred to third level ultrasound clinic. Eur J Obstet Gynecol Reprod Biol. 1998;76(2):141-6. 
40. Barel O, Vaknin Z, Smorgick N, Reish O, Mendlovic S, Herman A, et al. Fetal abnormalities leading to third trimester abortion: nine-year experience from a single medical center. Prenat Diagn. 2009 Mar;29(3):223-8.

41. Dommergues M, Benachi A, Benifla JL, des Noëttes R, Dumez Y. The reasons for termination of pregnancy in the third trimester. BJOG An Int J Obstet Gynaecol. 1999;106(4):297-303.

42. Ramasauskaite D. Management of Pregnancy and Delivery in Prenatally Diagnosed Congenital Anomalies. In: Congenital Anomalies - From the Embryo to the Neonate. InTech; 2018.

43. Harrison MR. Management of the Fetus with a Correcteable Defect. J Perinat Med. 1984;12(s1):19-20.

44. Hill LM, Breckle R, Gehrking WC. Prenatal detection of congenital malformations by ultrasonography. Mayo clinic experience. Am J Obstet Gynecol. 1985;151(1):44-50.

45. Creasy MR, Alberman ED. Congenital malformations of the central nervous system in spontaneous abortions. J Med Genet. 1976 Feb 1;13(1):9-16.

46. Moorthie S, Blencowe H, Darlison MW, Lawn J, Morris JK, Modell B, et al. Estimating the birth prevalence and pregnancy outcomes of congenital malformations worldwide. J Community Genet. 2018 Oct 14;9(4):387-96.

47. Weichert J, Hartge D, Krapp M, Germer U, Gembruch U, Axt-Fliedner R. Prevalence, characteristics and perinatal outcome of fetal ventriculomegaly in 29,000 pregnancies followed at a single institution. Fetal Diagn Ther. 2010;27(3):142-8.

48. Tomai XH, Jasmine TX, Phan TH. Antenatal ultrasonography findings and magnetic resonance imaging in a case of Pena-Shokeir phenotype. Ultrasound. 2017;25(2):115-9.

49. Gagnon A, Wilson RD, Allen VM, Audibert F, Blight C, Brock J-A, et al. Evaluation of Prenatally Diagnosed Structural Congenital Anomalies. J Obstet Gynaecol Canada. 2009 Sep;31(9):875-81.

50. Wataganara T, Grunebaum A, Chervenak F, Wielgos M. Delivery modes in case of fetal malformations. J Perinat Med. 2017 Jan 1;45(3).

51. Kaasen A, Tuveng J, Heiberg A, Scott H, Haugen G. Correlation between prenatal ultrasound and autopsy findings: A study of second-trimester abortions. Ultrasound Obstet Gynecol. 2006;28(7):925-33.

52. Boyd PA, Tondi F, Hicks NR, Chamberlain PF. Autopsy after termination of pregnancy for fetal anomaly: Retrospective cohort study. Br Med J. 2004;328(7432):137-40.

53. Akgun H, Basbug M, Ozgun MT, Canoz O, Tokat F, Murat N, et al. Correlation between prenatal ultrasound and fetal autopsy findings in fetal anomalies terminated in the second trimester. Prenat Diagn. 2007 May;27(5):457-62.

54. Isaksen C V., Eik-Nes SH, Blaas HG, Tegnander E, Torp SH. Comparison of prenatal ultrasound and postmortem findings in fetuses and infants with congenital heart defects. Ultrasound Obstet Gynecol. 1999;13(2):117-26.

55. Whitby EH, Paley MN, Cohen M, Griffiths PD. Postmortem MR imaging of the fetus: An adjunct or a replacement for conventional autopsy? Semin Fetal Neonatal Med. 2005;10(5):475-83.

56. Ros PR, Li KC, Vo P, Baer H, Staab E V. Preautopsy magnetic resonance imaging: Initial experience. Magn Reson Imaging. 1990;8(3):303-8.

57. Brookes JAS, Hall-Craggs MA, Sams VR, Lees WR. Non-invasive perinatal necropsy by magnetic resonance imaging. Lancet. 1996;348(9035):1139-41.

58. Sankar VH, Phadke SR. Clinical utility of fetal autopsy and comparison with prenatal ultrasound findings. J Perinatol. 2006;26(4):224-9.

59. Farmer D, Sitkin N, Lofberg K, Donkor P, Ozgediz D. Surgical Interventions for Congenital Anomalies. In: Disease Control Priorities, Third Edition (Volume 1): Essential Surgery. The World Bank; 2015. p. 129-49.

60. Adeleye AO, Olowookere KG. Central nervous system congenital anomalies: A prospective neurosurgical observational study from Nigeria. Congenit Anom (Kyoto). 2009;49(4):258-61.

61. Brand IR, Kaminopetros P, Cave M, Irving HC, Lilford RJ. Specificity of antenatal ultrasound in the Yorkshire Region: a prospective study of 2261 ultrasound detected anomalies. BJOG An Int J Obstet Gynaecol. 1994 May;101(5):392-7. 